\title{
Computer Analysis
}

National Cancer Institute

\section{Source}

National Cancer Institute. Computer Analysis. NCI Thesaurus. Code C18191.

The application of computing capabilities in solving complex mathematical calculations. 